\title{
GLOBAL AND LOCAL COLLABORATORS: A STUDY OF SCIENTIFIC COLLABORATION
}

\author{
Miranda lee PaO \\ School of Information and Library Studies, The University of Michigan, \\ 550 East University, Ann Arbor, MI 48109, U.S.A.
}

\begin{abstract}
Increased co-authorship in schistosomiasis has been shown to be associated with research funding. The small core of grantees is highly prolific. Furthermore, strong evidence points to the existence of two types of co-authors, namely, the globals who appear to co-author with individuals outside their own group, and the locals who are limited in their formal collaboration. The globals constitute a small group of highly productive scientists, whereas there is a large pool of lower-rank locals. The data supports the theory that scientific collaboration serves as a means to advance research, as well as a mechanism to increase the visibility and authorship of the highly productive.
\end{abstract}

\section{INTRODUCTION}

Scientific collaboration is commonly associated with "Big Science." Two characteristics have been specifically cited, namely, that somehow it is related to research funding and that it directly contributes to the stratified nature of science. Although Price alluded to the rise of support of large research projects as a possible force in the increase of co-authored works, it was several years later that he posited that collaboration might be a function of financial rather than intellectual dependence $[1,2]$. He also argued that collaboration is a mechanism by which the highly productive maintain visibility while making the best use of scientific personnel. This paper offers empirical evidence on the relationship among scientific co-authorship, funding, and productivity.

\section{Research funding}

In this paper, scientific collaboration refers to co-authorship, the formal acknowledgement of joint research. Although collaboration has existed since the beginning of science, it was noteworthy that its significant growth rate in recent decades was matched by the exponential increase in research dollars [3-5]. In a comprehensive study of scientific collaboration, Beaver and Rosen advanced a general theory that scientific collaboration is a response to professionalism. Confirmation was sought by testing of several of its consequences, using publication data of the 17 th through the 20 th centuries. The term "professionalism" refers to a complex of dynamic processes involving organizations and scientists individually and collectively with respect to both the scientific group and society at large. There are many outward signs of professionalization. For example, in the early stages of professionalism, a loosely linked cluster of individuals would establish their identity as a distinct community by the formation of a separate organization or research laboratory. They would declare independence by allowing only those specially trained to contribute to their field. Further distinction might be enhanced by a journal devoted to the subject. Professionalism also sets criteria for the new entrants and formalizes rules of behavior among members. It establishes interactions between the group and outsiders. In the progression to more mature stages, typically the group gains increasing recognition by society. Some obvious gauges of professional maturation of an individual or a field can take the form of notices in the popular presses regarding new discoveries and innovative applications and national and international prizes and awards. Society, in turn, recognizes the value and contribution made by the profession by having scientists and scholars serve as advisors in various capacities.

This publication is supported in part by a NIH grant RO1-LM-04680 from the National Library of Medicine. 
Another visible form of societal recognition is the size of budget allocated by governmental and private funding agencies to research on the subject. To ascribe financial support as the sole cause of the increase of scientific collaboration is difficult. A number of contributing factors may play a role. For example, large-scale projects require elaborate laboratories, sophisticated equipment, and/or expert input from several disciplines, thus necessitating teamwork. Yet, without external support, major initiatives such as the $\mathrm{Hu}$ man Genome Project might never be planned in the first place. Price suggested that the amount of co-authorship in a field is directly linked to the size of financial support made to researchers working and publishing in that subject area [6]. He cited data from an unpublished work by Hirsch and Singleton on two sociological journals as evidence supporting his hypothesis [7]. Patel analyzed 7,908 papers from four sociological journals [8]. He found that one in four multi-author papers was funded, as compared to one in very 14 single-author papers. Based on a total of 395 papers examined, Heffner reported the relationship between research support and co-authorship to be statistically significant for biological science and for chemistry, but not for political science and psychology [9]. Among the 881 research papers published in 1986 in library and information science, significantly higher co-authorship was found associated with sponsored research [10]. Price speculated that it is highly likely that a heavily subsidized soft subject would become as collaborative as another highly collaborating scientific field [6]. Indeed, there are indications that although single authorship is the norm in musicology, the infusion of research dollars to computational musicology, or computer-aided musicological studies, was found linked with a substantially higher rate of multiple authorship [11]. Thus, research support may not be the sole cause, but it appears to be at least one explanatory variable for collaboration which in turn stimulated increased authorship for those who co-authored.

\section{Scientific stratification}

In explaining the functions of teamwork, Price thought that collaboration serves a dual role in that it effectively increases the productivity of the highly prolific while it manages to squeeze papers out of the lower-rank members [1]. His 1966 data on 555 authors showed that high producers with 14 or more papers were also the most collaborating, with 12 or more collaborators in a five-year period studied. Those who worked alone or with only one other scientist werc unable to produce more than four papers in the same period [2]. Zuckerman's well-known study of Nobel laureates showed a high correlation between collaboration and productivity [12]. In Pao's study of the literature of computational musicology, although only $38 \%$ of its authors took part in co-authored activities, the most collaborative were also the most productive $[11,13]$.

Others have studied the upward moves of scientists in organizational structures [14]. They found that as one acquires higher status, one also starts to relinquish the actual conduct of research, while slowly assuming more of the role of the supervisor. Higher status scientists in supervisory positions have more access to scientific personnel and money. They control the research direction by setting goals and in planning the project while delegating research tasks to lower-status scientists. Yet they assert their leadership in interpreting and reporting of the research results. Working on different projects at the planning and interpreting stages without playing a major role at the actual execution stage allows them to make maximum use of their time and energy. Furthermore, supervisory positions confer greater ease of authorship and co-authorship. This role change results in a gain in publication productivity. It is not uncommon to observe clusters of student and staff scientists around key investigators. This phenomenon lends support to the theory that collaboration is a clear means to advance in the professional hierarchy of science [4]. From the standpoint of the scientist, collaboration is a mechanism to advance research, as well as a means to increase productivity and visibility. Thus teamwork involves the optimal utilization of a larger pool of personnel with lower productivity. A highly stratified system of science results.

Review of previous works on scientific collaboration showed that empirical studies of collaboration have been limited in sample size and in the depth of analysis. There are several contributing factors. First, not all databases and secondary publications include all 
authors. For example, there is a ceiling of 10 names per paper in recent years of the MEDLINE database. The task of tracking individual authors in multi-authored publications is so tedious and labor-intensive that few can afford the time or effort. Using all co-authors instead of merely primary authors also means an increase of an order of magnitude in the amount of work associated with data collection and manipulation. Often one is reduced to some simple indicators, such as the average number of names per paper, as a rough gauge for the extent of collaboration. Lastly, the number of errors in the name field in published sources is non-trivial. Proper attribution of authorship involves extensive manual checking of inconsistencies and errors.

Thus, the empirical verification of the relationship between co-authorship and research funding has been based on limited data. The impact of co-authorship on the stratification of science remains largely untested. As part of a study on the impact of research funding on a major tropical disease, an extensive bibliography of schistosomiasis papers published 1966-1986 was collected. Schistosomiasis is a tropical disease affecting a substantial number of people, especially in the developing countries. Research has enjoyed substantial support from many sources. The authorship data from a major subject literature which has been funded for a long period of time offers a unique opportunity to test Price's hypothesis that collaboration is a function of research funding and is directly related to the rise of Big Science. This paper presents analyses of author groups with respect to co-authorship, research funding, and productivity in order to support or to refute the claims that:

1. research funding is linked positively with co-authorship; and

2. mass co-authorship directly contributes to scientific stratification, in that relatively few of the highly prolific co-author with a large number of those minimally productive.

\section{EMPIRICAL DATA}

Through the generous cooperation of the World Health Organization, the National Institutes of Health, the Edna McDonnell Clark Foundation, and the Rockefeller Foundation, funding data were made available to the study. The four agencies have been responsible for the major support of schistosomiasis research for over one and a half decades. Data from 1972-1986 were provided. Each award identifies the principal investigator(s), the level and period of the award, and the title of the funded project. A total of 351 individuals were identified as grantees. Only $26 \%$ received awards from two or more agencies.

Using the broad subject heading for schistosomiasis with all of its subheadings and related headings, the total literature of 8,127 bibliographic records for the period 1966-1986 was downloaded from the MEDLINE database. Considerable effort was expended on cleaning the data set. This data set was subjected to several iterations of checking in order to eliminate and consolidate inconsistencies and errors in author names, including misspellings, transpositions, omissions, and additions of extraneous characters. Six percent of the author names were corrected. As a result of consolidation and correction, 9,908 unique authors were identified who contributed to the literature of 8,034 publications with known authorship.

In a 1966 paper, Price and Beaver identified the "authorship" count of a given author as the total number of times that author's name appeared in the bylines of papers [2]. The total "fractional productivity" of an author is the sum of $1 / n$ of all papers in which his or her name appeared as an author, where $n$ is the number of authors sharing authorship of the paper. Thus for a group of multi-authored papers, the total number of authorships of all contributing authors exceeds the number of papers. Since then, many have adopted the terminology used by Lindsey [15]. He distinguished three types of productivity counts: normal count, straight count, and adjusted count. Normal count is equivalent to "authorship" count as used by Price and Beaver. Straight count tallies only those names that appeared as the primary author of a paper, eliminating those who only published as secondary authors. This count should equal the total number of papers with known authorship. Similarly, adjusted count, favored by Lindsey, required the computation of the equivalent of 
Table 1. Productivity for the funded and nonfunded sets

\begin{tabular}{|c|c|c|c|c|}
\hline & \multicolumn{2}{|c|}{ Average productivity } & \multirow{2}{*}{$\begin{array}{l}\text { Avg. yearly } \\
\text { names/paper }\end{array}$} & \multirow[b]{2}{*}{ Coauthored work } \\
\hline & Normal count & Straight count & & \\
\hline Total literature & $\begin{array}{c}2.42 \\
(n=9,908)\end{array}$ & $\begin{array}{c}2.11 \\
(n=3,801)\end{array}$ & 2.92 & $77 \%$ \\
\hline Funded subset & $\begin{array}{c}3.74 \\
(n=2,535)\end{array}$ & $\begin{array}{c}3.07 \\
(n=970)\end{array}$ & 3.05 & $87 \%$ \\
\hline Nonfunded subset & $\begin{array}{c}1.82 \\
(n=7,936)\end{array}$ & $\begin{array}{c}1.68 \\
(n=3,016)\end{array}$ & 2.84 & $71 \%$ \\
\hline
\end{tabular}

$n=$ number of authors included.

the author's "fractional productivity" for each paper. For this study, several computer programs were written to extract data from the author field by various matching algorithms. Frequency distributions by normal and straight count were created from various subsets of the schistosomiasis bibliography.

\section{ANALYSIS}

The schistosomiasis file contains 8,034 records. Names of 9,908 unique contributors appeared a total of 23,951 times. From the total data set, a subset was created by extracting papers bearing names of at least one of the grantees. Although no attempt was made to examine the papers to verify if work reported in every paper was funded, the 2,980 papers are associated with the group of 287 contributing grantees. Only two grantees did not co-author, and 64 did not publish on the subject. The small group of grantees co-authored with 2,248 collaborators producing a total of 9,470 authorships. The remaining set of 5,054 publications contributed by 7,936 authors can be labeled the nonfunded set. Henceforth, the two sets will be referred to as the "funded set" and the "nonfunded set," respectively. Overall the funded set is more productive in both the normal and straight counts (see Table 1).

\section{Collaboration-Average names per paper}

Focusing on the publication itself, the number of names per paper has been used as a rough indicator of the degree of collaboration by Beaver and Rosen [5]. A comparison of 24 subjects was made from data obtained from the 1970 Source Journal Statistics from the Science Citation Index. (III) Mathematics and astronomy were found to have the lowest collaboration in the sciences, corroborating the common perception that these two subjects were chronically under supported. The study of cardiovascular systems had a high of 2.74, while the average number of names per paper for the schistosomiasis literature in 1970 was computed to be 2.40 . This subject is highly collaborative as compared with other biomedical literatures. Furthermore, an overwhelming $94 \%$ of the authors co-authored in at least one paper. The findings corroborated with those reported by Yitzhaki and Ben-Tamar in their large sample study of papers in the Journal of Biological Chemistry [16].

Since only four papers were indexed for 1966 and 1967, they were deleted from further consideration. Computing the names per paper from the yearly output, a definite upward trend is observed in Fig. 1, giving some support to Price's speculation that science is becoming more collaborative. Similarly, subfiles for each year were created from both the funded and nonfunded sets. Although somewhat higher values for the funded set are shown, there is only an average of 0.27 additional names per paper. The number of names per paper overall and for every year are similar for both subsets (see Table 1). It should be noted that the data presented here are the results of tabulations of occurrences of any names, regardless of the number of unique authors involved. 


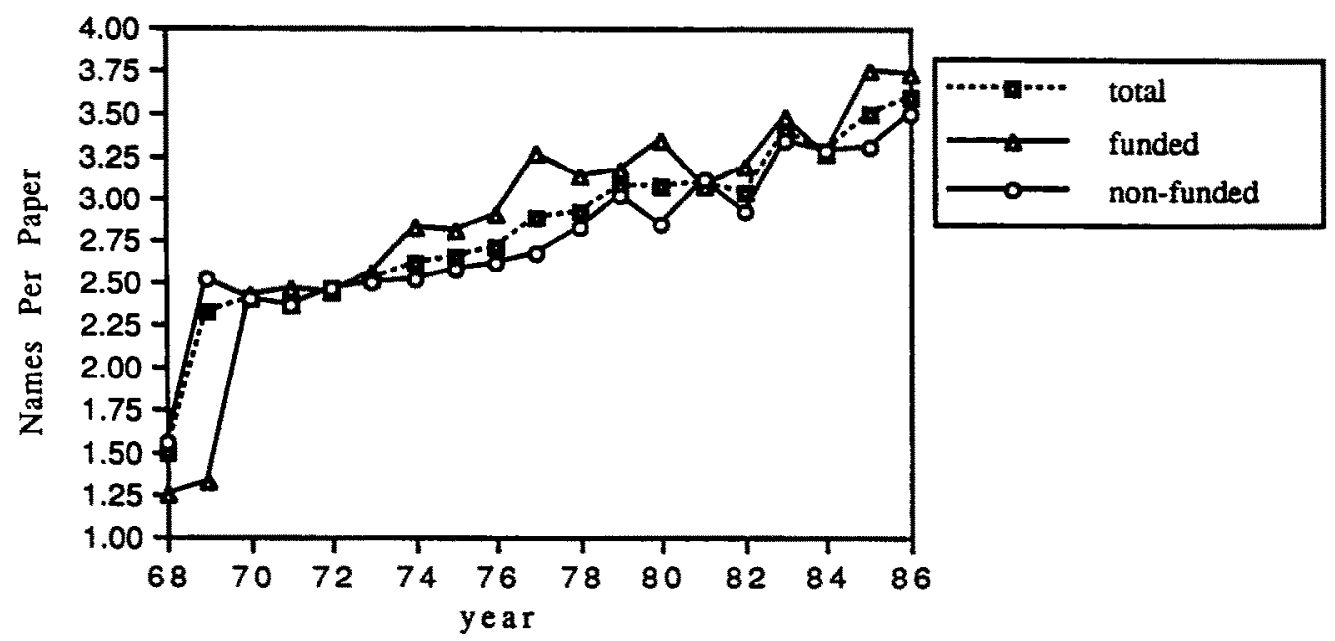

Fig. 1. Average names per paper.

\section{Collaboration-Proportion of co-authored papers}

The actual proportion of co-authored publications also indicates the extent of collaboration, although the percentage of papers having a single author has been used as a substitute. In Chemical Abstracts, 1900-1960, a steady decline of single-author papers was presented to give a sense of the increasing trend of collaborating papers on the subject [1]. As with the papers in the Journal of Biological Chemistry, a trend of similar increase of co-authored papers in schistosomiasis is shown in Fig. 2 with data computed from the yearly output [16]. A total of $77 \%$ of all schistosomiasis papers were co-authored. A much higher percentage (87\%) was found in the funded, as compared with $71 \%$ for the nonfunded set (see Tables 1 and 2). Comparison of the yearly output shows that a definite growth of co-authored papers is associated with the funded set starting after 1970, when the substantial research funding began.

\section{Collaboration -Average number of unique names per paper}

However, the number of names per paper is computed from the occurrences of names, regardless of the number of unique names. A large value may mean that there are many

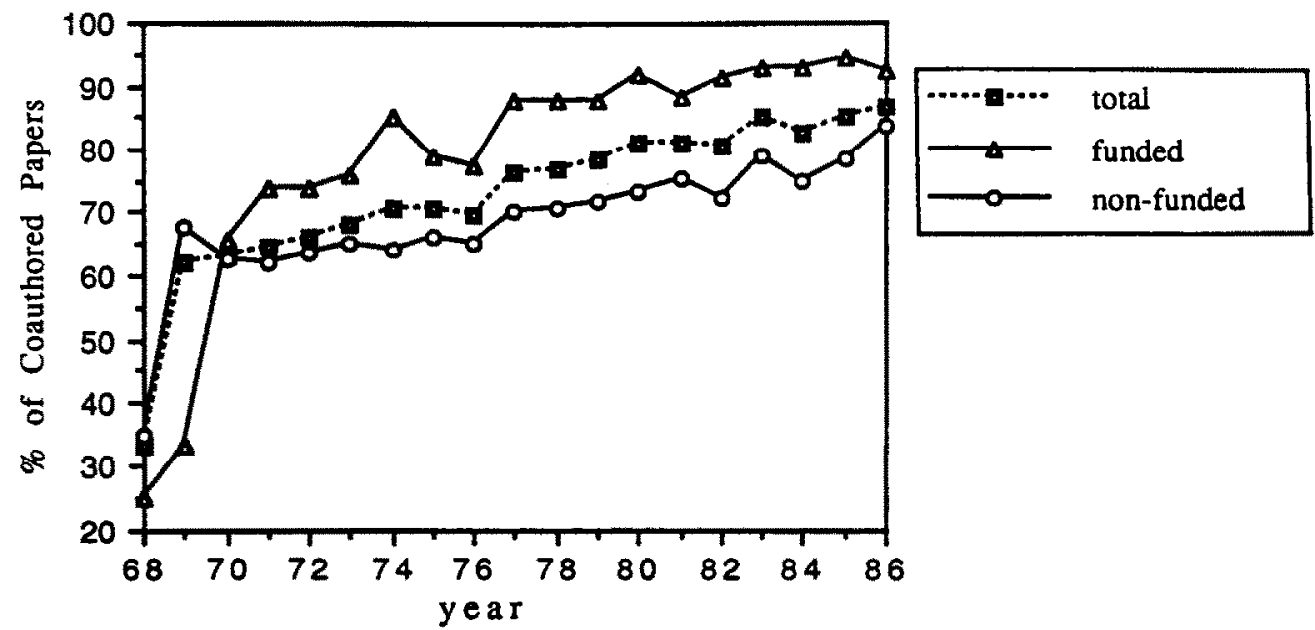

Fig. 2. Percentage of coauthored publications. 
Table 2. Percentages of co-authored publications in the funded and nonfunded sets

\begin{tabular}{cccc}
\hline Year & $\begin{array}{c}\text { Total } \\
\text { literature }\end{array}$ & $\begin{array}{c}\text { Funded } \\
\text { subset }\end{array}$ & $\begin{array}{c}\text { Nonfunded } \\
\text { subset }\end{array}$ \\
\hline 1968 & 33.3 & 25.0 & 35.0 \\
1969 & 62.2 & 33.3 & 67.7 \\
1970 & 63.0 & 65.4 & 62.7 \\
1971 & 64.8 & 73.7 & 62.2 \\
1972 & 66.4 & 73.9 & 63.4 \\
1973 & 68.1 & 75.9 & 65.1 \\
1974 & 70.9 & 84.9 & 64.0 \\
1975 & 70.6 & 79.1 & 66.1 \\
1976 & 69.6 & 77.6 & 65.2 \\
1977 & 76.5 & 87.9 & 70.3 \\
1978 & 76.8 & 87.9 & 70.9 \\
1979 & 78.3 & 87.8 & 72.0 \\
1980 & 81.1 & 91.7 & 73.1 \\
1981 & 81.0 & 88.3 & 75.3 \\
1982 & 80.5 & 91.3 & 72.4 \\
1983 & 85.2 & 92.7 & 79.2 \\
1984 & 82.7 & 92.7 & 74.8 \\
1985 & 85.0 & 94.3 & 78.3 \\
1986 & 86.8 & 92.2 & 83.4 \\
\hline
\end{tabular}

multi-authored papers in this subject involving many different authors. It may also mean that there are as many multi-authored papers, but they are contributed by a smaller group of highly productive individuals. Therefore, the finding that over three decades the biomedical literature has maintained a steady 2.3 names per paper can be misleading in terms of the size of the active manpower pool [17]. Similarly, the percentage of co-authored works also does not take into account the pool of contributors or the intensity of collaboration. A comparison of the average number of unique authors per paper gives an indication of the relative size of the two personnel pools. The addition of each new name would raise the proportion of unique authors per paper, whereas each additional appearance of any existing name would lower this valuc. For the nonfunded set, there werc 7,936 unique authors contributing 5,054 papers, resulting in an average of 1.57 authors per paper. On the other hand, 2,535 authors of the funded set contributed 2,980 papers, with an average of 0.85 author per paper. Yet the average numbers of unique authors per paper computed from the yearly output are 1.78 and 2.78 , higher than the overall values of 0.85 and 1.57 from the funded and nonfunded sets respectively, since many of the same authors published in

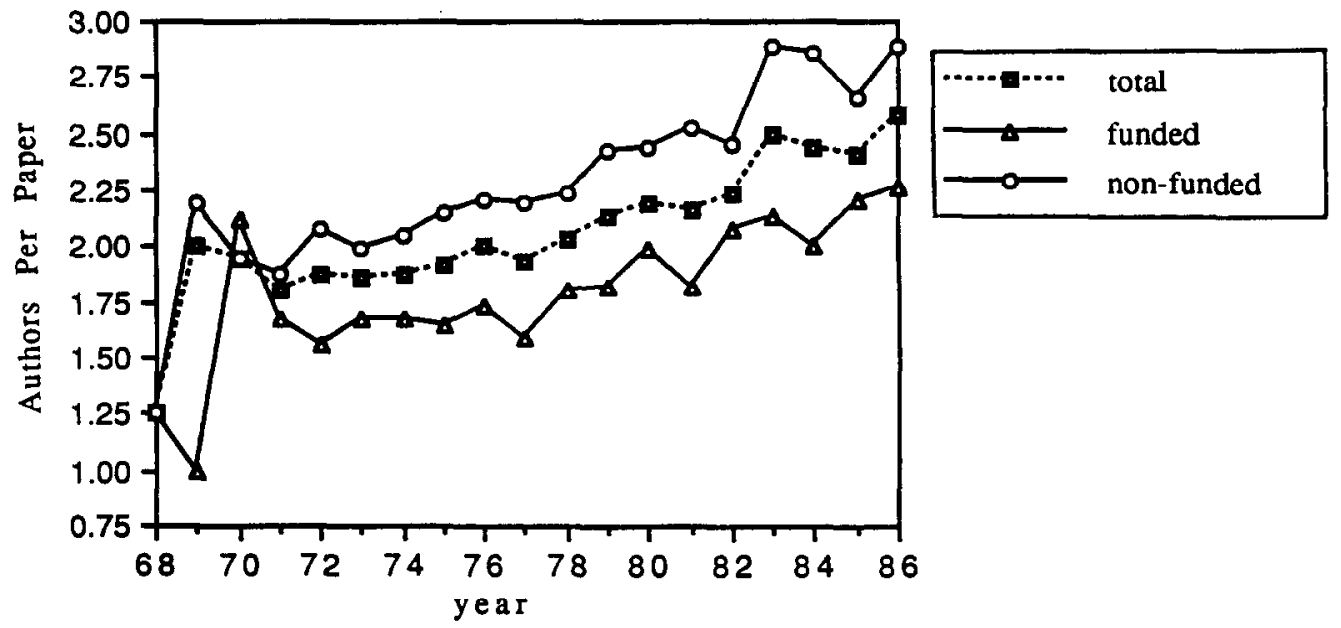

Fig. 3. Average authors per paper. 


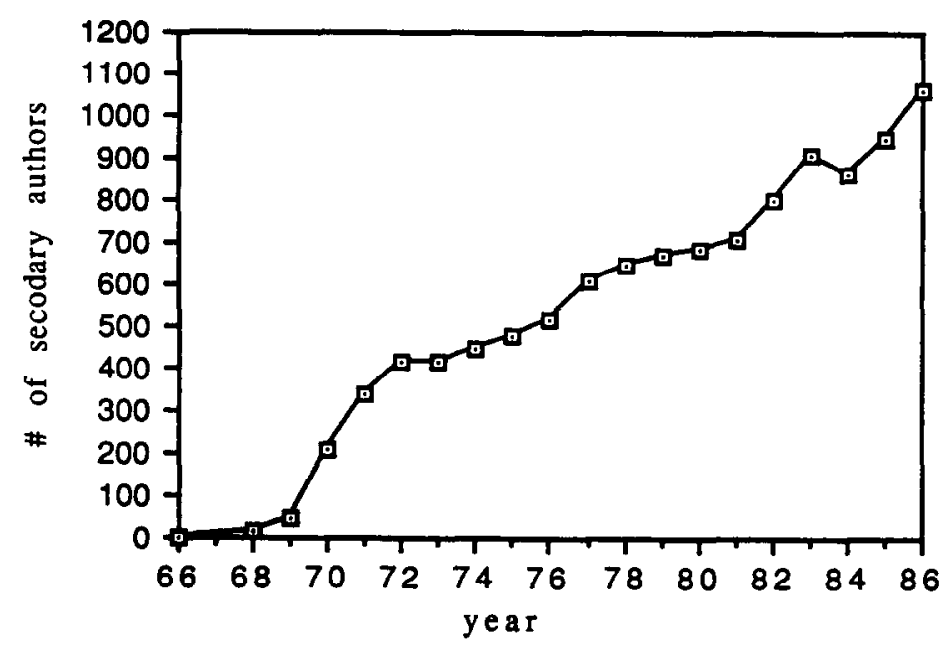

Fig. 4. Growth of secondary authors.

subsequent years. Figure 3 shows the higher number of authors in the nonfunded set. On the average, a paper in the nonfunded subset has an added 0.5 unique author. Although the difference between the funded and nonfunded sets is small, authors in the nonfunded group are less productive, and proportionally many more in this group have lower productivity. Figure 3 also points to a definite trend toward the involvement of an increasing number of authors.

\section{Evidence of secondary authors}

Since the average number of unique names per paper is similar between the funded and nonfunded literatures and the overall productivity of the funded set is higher, one expects to find many more lower-rank authors in the latter group. The less productive are likely to publish mainly as collaborating members. Those published only as secondary authors in the 20-year span were identified. A disproportionately large $62 \%$ of the schistosomiasis authors overall wrote only as secondary authors. Again the yearly output was examined. Although a mean of $64 \%$ wrote only as co-authors, a dramatic increase in recent years can be seen in Fig. 4. Figure 5 shows the proportions of secondary authors between the funded and nonfunded subsets from 1971 to 1986 . Although there are more secondary authors, there are only slight fluctuations in terms of proportions over the years. After 1971, an average of $3.8 \%$ of additional secondary authors was found in the nonfunded set.

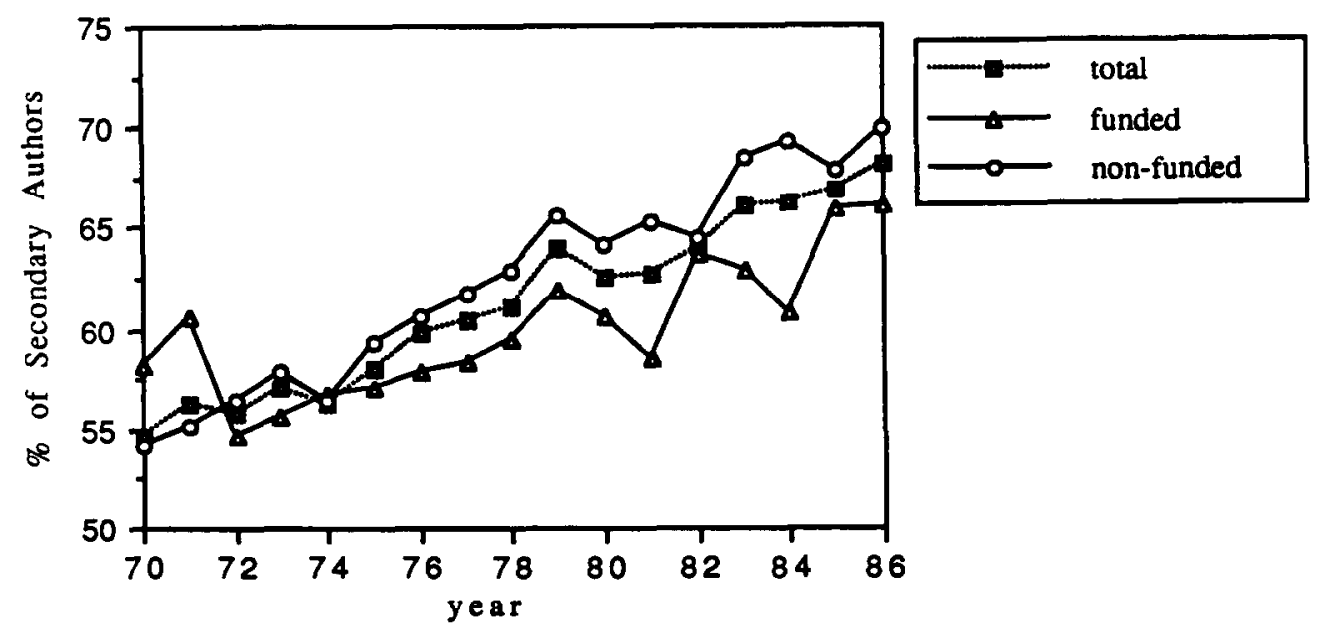

Fig. 5. Percentage of secondary authors. 


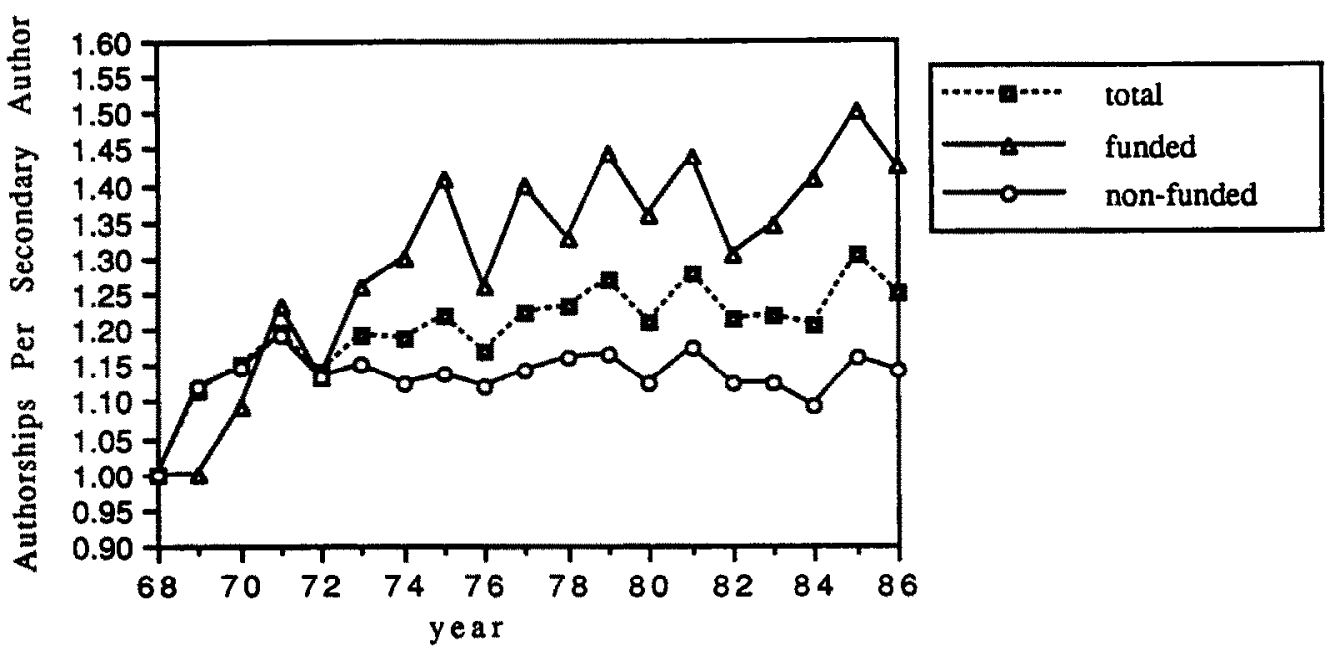

Fig. 6. Average authorships per secondary author.

Even without adjusting for fractional authorship, one would expect a lower productivity for the secondary authors. Using normal count, an average of 1.46 authorships per person is computed for the secondary authors in the entire data file, as compared with 3.95 for those who wrote as primary authors in one or more papers. The average number of papers per secondary authors are 1.68 and 1.37 for the funded and nonfunded sets, respectively. Figure 6 shows that although increasingly more secondary authors were recruited, the average productivity within each of the three groups shows little fluctuation. As expected, significantly lower productivity for the secondary authors in the nonfunded set is shown.

\section{Grantees, collaborators, and non-associates}

To examine the productivity of funded researchers and those who collaborated with them directly or indirectly, the total 9,908 authors were separated into three groups: (1) 287 grantees, (2) 2,248 collaborators, and (3) 7,373 non-associates. A grantee is one whose name appeared in one of the funding lists in the period 1970-1986. A collaborator is one who has co-authored with at least one grantee in one or more papers. Finally, a non-associate is one who has not co-authored with any grantee. Two thirds of the authors were non-associates, with no direct ties to any grantee. These groups were examined in terms of productivity and collaboration.

Both the normal and straight count methods were used to assess author productivity. Table 3 shows that the grantees are extraordinarily productive in terms of both methods of attribution. The average productivity of both the grantees and the collaborators are well

Table 3. Productivity of grantees, collaborators, and non-associates

\begin{tabular}{lcc}
\hline & \multicolumn{2}{c}{ Average productivity } \\
\cline { 2 - 3 } & Normal count & Straight count \\
\hline Total literature & 2.42 & 2.11 \\
Grantees & $(n=9,908)$ & $(n=3,801)$ \\
Collaborators & 14.33 & 6.64 \\
Non-associates & $(n-287)$ & $(n=240)$ \\
& $(n=2,248)$ & 2.69 \\
& 1.64 & $(n=902)$ \\
& $(n=7,373)$ & $(n=2,668)$ \\
\hline
\end{tabular}


above the average of the schistosomiasis authors as a whole. Productivity distribution is skewed toward the grantees and their associates. Nearly half of all papers were the product of the grantees and their collaborators. Yet they consisted only of $25 \%$ of all authors. The remaining half can be credited to the non-associates, who made up three quarters of all authors. Counting only the primary authors, the grantees and their collaborators are also more productive than the non-associates.

\section{Global and local collaborators}

Subramanyam listed six types of collaboration [18]. As far as a formal acknowledgement by co-authorship is concerned, two types of co-authorship have been referred to [4]. Two individuals may form an alliance as equal partners in a publication; they jointly develop and conduct the research, and they share the research responsibility. A distinguished example of this type of collaboration is the celebrated work by the Nobelists Watson and Crick. Many examples can be found in interdisciplinary research such as those in medical informatics. Teamwork is sustained by collaboration of researchers with medical and computer knowledge. This equal partnership pools two areas of expertise. Yet such close collaboration of independent scientists sometimes results in separate publications [19].

The master-apprentice model reflects another type of co-authorship. In scientific fields, teacher-pupil and supervisor-assistant relationships are common. The shared responsibility in many papers, especially those based on doctoral dissertations of the junior authors, is different from teamwork of otherwise independent researchers. These co-authors depend on the senior member for intellectual or financial support. The same may be found in teamwork produced in the research laboratories where staff scientists work under the direction of senior scientists.

Beaver and Rosen conjectured that rivalry and competition inhibit partnership of the first kind, whereas by collaborating with a junior member, the contribution of the mentor is less likely to be questioned. Empirically little data have been collected to confirm or refute this thesis, since clear distinction between the two models of collaboration is difficult to ascertain. In this paper, a distinction is made based on the following. As equal partnership implies independence, the individual is not limited to one circle of scientists. If they collaborate, they are more likely to align with more than one group of investigators, thus serving as the link between two or more groups. They are global in outlook. The more mature globals are better equipped to transcend the boundaries of a single group. The locals, on the other hand, are more dependent on senior scientists and are limited in terms of contact and collaboration.

For the sake of convenience local and global are labels used to distinguish the two collaborator types. Within each of the three groups of grantees, collaborators, and nonassociates, two subgroups were identified. The locals are those who restricted their coauthorship within the group, and the globals are those who, in addition to collaborating with members of their own groups, also co-authored with members of another group.

Among the 287 grantees, there were ten locals. In fact, only two co-authored, each of whom produced a single two-author paper on the subject. Eight only published singleauthor papers. The remaining 277 were globals who co-authored with members outside the grantee group or published with both grantees and outsiders. Table 4 shows that although as a group the grantees are highly productive, the difference in productivity between the locals and globals is striking. The performances of the global grantees are indeed impressive. The average global grantee published 15 papers. Names of each of 240 grantees appeared as senior authors an average of six times. It is noteworthy that the productivity of the local grantees is 1.30 and 1.40 in normal and straight counts respectively, among the lowests of all the author groups examined (see Table 4). They are even lower than the averages derived from the total literature.

The 2,248 collaborators were also divided into two groups. The local collaborators consist of 1,725 members who only co-authored with grantees. Only 523, fewer than one quarter, are global collaborators. In addition to collaborating with the grantees, they also co-authored with scientists outside the grantee circle. Except for the global grantees, the global collaborators are by far the most productive. Their productivity ranges from a low 
Table 4. Productivity of globals and locals

\begin{tabular}{|c|c|c|c|c|}
\hline & \multicolumn{4}{|c|}{ Average productivity } \\
\hline & \multicolumn{2}{|c|}{ Globals } & \multicolumn{2}{|c|}{ Locals } \\
\hline & Normal count & Straight count & Normal count & Straight count \\
\hline Grantees & $\begin{array}{c}14.81 \\
(n=277)\end{array}$ & $\begin{array}{c}6.82 \\
(n=232)\end{array}$ & $\begin{array}{c}1.30 \\
(n=10)\end{array}$ & $\begin{array}{c}1.40 \\
(n=8)\end{array}$ \\
\hline Collaborators & $\begin{array}{c}8.21 \\
(n=523)\end{array}$ & $\begin{array}{c}4.07 \\
(n=373)\end{array}$ & $\begin{array}{c}2.01 \\
(n=1,725)\end{array}$ & $\begin{array}{c}1.72 \\
(n=529)\end{array}$ \\
\hline Non-associates & $\begin{array}{c}2.35 \\
(n=1,695)\end{array}$ & $\begin{array}{c}2.10 \\
(n=484)\end{array}$ & $\begin{array}{c}1.43 \\
(n=5,678)\end{array}$ & $\begin{array}{c}1.37 \\
(n=2,184)\end{array}$ \\
\hline
\end{tabular}

of 2 to a high of 80 papers. Evidence of independence may be seen. A random check of six productive globals indicates that they are indeed well known in the field, even though they were not identified as recipients of grant awards from the four agencies. The top seven authors accounted for $\mathbf{4 2 3}$ papers. The average productivity of the local group is well below that of the average from the schistosomiasis literature at large. The difference between the two groups of collaborators is substantial, giving credence to the existence of two types of collaborators.

Similarly, two groups of non-associates were also identified. A global non-associate is an indirect collaborator, who has not co-authored with any grantee, but has co-authored with at least one collaborator. Thus, an indirect link has been established with the grantee group. Only $23 \%$ of the non-associates were globals. Whereas $77 \%$ of the non-associates had no linkage to the grantees directly or indirectly, the globals attained productivity counts of 2.35 and 2.10 in normal and straight counts, respectively. These values are nearly the averages of 2.42 and 2.11 for the schistosomiasis authors as a whole. In contrast, the local non-associates have low productivity. Thus there seem to be two types of co-authors. The globals, who are more collaborative, are also much more productive. They are fewer in number. For them, it seems that the closer the collaborative tie is to the grantees, the more productive is the group. This gives support to the contention offered by Beaver and Rosen that there are less chances to establish equal partnership in collaboration. Overwhelming evidence exists that the grantees constitute an exceptionally prolific group, most of whom are globals.

\section{CONCLUSIONS}

This analysis offers empirical evidence to support Price's claim that collaboration is associated with research funding. The contributing grantees are highly collaborative and prolific. Although over $\mathbf{9 4 \%}$ of the authors engaged in co-authorship, the subset of schistosomiasis literature associated with supported researchers is more collaborative than those not linked with research funding. A general analysis of the extent of collaboration was sought in terms of the average number of unique names per paper, as well as the proportion of co-authored works. Although both give only a general indication of coauthorship, the proportion of co-authored works over time is a good index of collaborative effort. A substantially larger group of secondary authors with minimal productivity is found in the nonfunded set.

Regardless of the methods of attribution, the grantees as a whole are extraordinarily prolific. Productivity appears to fall in a hierarchy. Members with higher yields have stronger links to the grantees. Although higher levels of collaboration are shown in the funded group, the data showed that there is indeed a huge pool of secondary authors with low productivity.

Price maintained that the scientific elite maintains and increases its high profile by collaboration with authors of marginal productivity. A highly skewed productivity distribu- 
tion is characterized by two distinct groups, a highly productive small group and a large population of average researchers. This phenomenon is supported by the productivity of the globals and locals. The differential between the highly productive globals and the marginally productive locals points to the two types of collaborators referred to by Beaver and Rosen. The globals do not limit their collaboration to a single stratum and they are consistently more productive than the locals. This provides strong evidence that collaboration is a means to advance research and to multiply publication capacity for the productive members. Thus it directly contributes towards science stratification.

Acknowledgement - The author acknowledges the generosity and cooperation accorded by the World Health Organization, the National Institute of Health, the Edna McDonnell Clark Foundation, and the Rockefeller Foundation. The author is also grateful for the suggestions and comments made by Professor Judith Weedman.

\section{REFERENCES}

1. Price, D. deSolla Little Science, Big Science. New York: Columbia University Press; 1963.

2. Price, D. deSolla; Beaver, D. Collaboration in an invisible college. American Psychologist, 21: 1011-1018; 1966.

3. Beaver, D. deB.; Rosen, R. Studies in scientific collaboration: Part I. The professional origins of scientific co-authorship. Scientometrics, 1(1): 65-84; 1978.

4. Beaver, D. deB.; Rosen, R. (1979). Studies in scientific collaboration: Part II. Scientific co-authorship, research productivity, and visibility in the French scientific elite, 1799-1830. Scientometrics, 1(2): 133-149; 1979.

5. Beaver, D. deB.; Rosen, R. Studies in scientific collaboration: Part III. Professionalization and the natural history of modern scientific co-authorship. Scientometrics, 1(3): 231-245; 1979.

6. Price, D. deSolla (1970). Citation measures of hard science, soft science, technology and nonscience. In: Nelson, C.E.; Pollack, D.K., editors. Communication among scientists and engineers. Lexington, MA: D.C. Heath; 1970: 3-22.

7. Hirsch, W.; Singleton, J. Research support, multiple authorship, and publications in sociological journals, 1936-1964. Lafayette, Indiana: Purdue University; Unpublished paper; [1964].

8. Patel, N. Collaboration in the professional growth of American sociology. Social Science Information, 12: $77-92 ; 1973$.

9. Heffner, A.G. Funded research, multiple authorship, and subauthorship collaboration in four disciplines. Scientometrics, 3(1): 5-12; 1981 .

10. Hart, R.; Carstens, T.; Lacroix, T.M.; May, K.R. Funded and non-funded research-Characteristics of authorship and patterns of collaboration in the 1986 library and information science literatures. Library and Information Science Research, 12: 71-86; 1990.

11. Pao, M.L. Collaboration in computational musicology. Journal of the American Society for Information Science, 33: 38-43; 1982 .

12. Zuckerman, H.A. Nobel laureates in science: Patterns of productivity, collaboration and authorship. American Sociological Review, 32: 391-403; 1967.

13. Par . M.L. Co-authorship as communication measure. Library Research, 2: 327-338: 1981.

14. Knorr, K.D.; Mittermeir, R., Aichholzer; G., Waller, G. Individual publication, productivity as a social position effect in academic and industrial research units. In: Andrews, F.F., editor. Scientific productivity: The effectiveness of research groups in science. Cambridge: Cambridge University Press; 1979: 55-94.

15. Lindsey, D. Productivity, citation measures in the sociology of science: The problems of multiple authorship. Social Studies of Science, 1: 101-125; 1980.

16. Yitzhaki, M.; Ben-Tamar, D. Multiple authorship in biochemistry and other fields. In: Egghe, L.; Rousseau, R., editors. Informetrics 89/90. The Netherlands: Elsevier; 1990: 373-389.

17. Clarke, B.L. Multiple authorship: Trends in scientific papers. Science, $143: 822-824 ; 1964$.

18. Subramanyam, K. Bibliometric studies of research collaboration: A review. Journal of Information Science, $6: 33-38 ; 1983$.

19. Stokes, T.D.; Hartley, J.A. Coauthorship, social-structure and influence within specialties. Social Studies of Science, 19; 101-125; 1989. 